REVISTA ANDALUZA DE ANTROPOLOGÍA.

NÚMERO 8: TURISMO DE BASE LOCAL EN LA GLOBALIZACIÓN

MARZO DE 2015

ISSN 2174-6796

[pp. 68-89]

http://dx.doi.org/10.12795/RAA.2015.i08.04

Fecha de Recepción: 01-11-2014

Fecha de Aceptación: 24-02-2015

\title{
TURISMO COMUNITARIO Y VINCULACIÓN RELIGIOSA EN LOS ANDES CENTRALES
}

\section{Jordi Gascón}

\author{
Instituto de Altos Estudios Nacionales
}

\section{Resumen.}

El turismo comporta cambios en los sistemas de creencias. Sin embargo, la relación entre turismo comunitario y cambio religioso ha sido poco estudiada. El artículo analiza este nexo a partir de un caso concreto: la Isla Amantaní, en el Sur de los Andes peruanos, de población indígena kichwa. En los '70 y ‘80, el sector social más beneficiado por el turismo comunitario tendió a adscribirse a la Iglesia Adventista del Séptimo Día. Los estrictos preceptos adventistas les permitieron inhibirse de participar en el oneroso sistema de fiestas. El sistema de fiestas otorgaba prestigio y poder político, pero también actuaba como un mecanismo redistribuidor de excendentes. De esta manera, este sector social pudo destinar los beneficios de su actividad a articularse mejor con el mercado. A mediados de los 90, los mecanismos tradicionales de obtención de poder político ya estaban en crisis, por lo que el rol del adventismo quedó obsoleto.

Palabras clave.

Turismo comunitario, cambio religioso, adventismo, sistema de fiestas, impacto socioeconómico, población kichwa, Andes

\section{Abstract.}

Tourism involves changes in belief systems. However, the relationship between community-based tourism and religious change has been little studied. The article 
analyzes this link from a specific case: Amantaní Island, in the Southern Peruvian Andes, whose population is indigenous kichwua. In the 70s and 80s, the social sector that received most of the benefits of community-based tourism tended to join the SeventhDay Adventist Church. Adventist strict precepts allowed to abstain from participating in the costly "Fiesta System". The "Fiesta System" gave prestige and political power, but it also acted as a redistributive mechanism economic. Thereby, this social sector could allocate the benefits of his activities to improve market linkages. A mid-90s, traditional mechanisms for obtaining political power were in crisis, and the role of Adventism had become obsolete.

\section{Keywords.}

Community-based tourism, religious change, adventism, fiesta system, socioeconomic change, kichwa people, Andes

Si bien en las dos últimas décadas la investigación académica sobre el turismo comunitario ha crecido exponencialmente, su relación con el cambio religioso y la cosmovisión local ha sido un aspecto poco analizado. Y cuando se ha tratado, generalmente lo ha sido de forma tangencial. Sin embargo, se sabe que el turismo es un vector de transformación de los sistemas de creencias (Cohen, 1971; Vukonic, 1996). De hecho, que el Turismo Comunitario participa en procesos de cambio religioso ha sido constatado por los escasos estudios que han tocado el tema (e.g. Gascón, 2005a; Jitpakdee \& Thapa, 2012; Litka, 2013).

El presente trabajo quiere incidir en este aspecto. Centrado en un caso localizado en el sur de los Andes peruanos (la Isla Amantaní), y en un determinado periodo (de la década de 1980 a mediados de la siguiente), el texto analiza como el desarrollo del Turismo Comunitario generó un proceso de conflictividad y restructuración política en la que jugó un papel importante el factor religioso. En el caso del sector más beneficiado por el Turismo Comunitario, determinada adscripción religiosa permitió activar estrategias acordes con sus intereses económicos. Estas estrategias ayudaron a colapsar el sistema tradicional de redestribución de excedentes para favorecer su articulación al mercado.El objetivo del texto es diseccionar cómo aconteció este proceso.

Se hace necesario, previamente, explicar qué entendemos por turismo comunitario. Como otros autores han señalado, aunque no tiene una definición analítica clara,es una actividad turística que se caracteriza más por la forma de organización que por su objetivo (Ruiz Ballesteros \& Solís Carrión, 2007).

En esta línea, y para el caso que nos ocupa, la definición de "recurso comunitario" con el que trabajan los estudios rurales puede darnos la clave. Un "común" o recurso comunitario es un recurso cuya propiedad o derecho de usufructo recae en una determinada 
población, que establece el control, gestión y regulación de su uso a través de estructuras y mecanismos de carácter autónomo y, normalmente, consuetudinario. Nadie que no sea miembro de esa población puede hacer uso de ese recurso, y todos los miembros de esa población (la comunidad) tienen derecho a su usufructo. Pero eso no quiere decir que los beneficios de ese recurso se distribuyan de forma equitativa. Ni siquiera que todos los miembros de la comunidad obtengan algún beneficio de él. A modo de ejemplo, aún en muchas sociedades rurales-campesinas se conservan espacios de pasto de propiedad comunitario. Eso indica que toda, y solo, la comunidad puede hacer uso de él. Pero quien tenga diez vacas obtendrá diez veces más beneficios del recurso que quien solo tiene una. $\mathrm{Y}$ puede haber quien quede excluido de sus beneficios por carecer de ganado. Como recuerda Netting (1997), quien tiene más recursos en propiedad privada suele obtener más beneficios de los recursos de propiedad comunitaria.

Desde este punto de vista, entendemos el turismo comunitario como la "comunalización" de este nuevo recurso, lo que no implica que todos aquellos que tienen derechos sobre él obtengan beneficios. En el caso que analizaremos, el turismo se planteó así al otorgar derechos de usufructo a todos los miembros de la comunidad y excluir a foráneos. Inicialmente, además, debía generar ingresos para toda los amantaneños. No obstante, aquellos que poseían más recursos en propiedad privada (o mejor dicho, un determinado recurso: el medio de transporte) acabaron siendo sus mayores beneficiarios.

\section{TURISMO COMUNITARIO EN AMANTANÍ ${ }^{1}$}

Amantaní es la isla más grande que Perú tiene en el Lago Titicaca. Sus habitantes son campesinos kichwas, y desde la Colonia hasta mediados del siglo pasado, sus tierras eran propiedad de diferentes haciendas. Un proceso de reclamación y lucha por la tierra que se alargó desde la década de los 30 a mediados de los 60, consiguió que los hacendados vendieran las propiedades a los campesinos.

Desde entonces, un fuerte crecimiento demográfico (entre 1950 y 1993, la población de la Isla pasó de 1.700 a 3.888 habitantes ), sumado a un sistema de herencia divisa, ha llevado a una disminución considerable de los recursos agro-pastoriles familiares, aumentando el grado de minifundización. Como en la mayor parte de la sierra andina, este contexto ha impulsado la migración. Un proceso que ya se había iniciado en el periodo de compraventa de las haciendas, pues obligó a muchos amantaneños a buscar fuentes de ingresos monetarizadas para poder adquirir lotes de tierras. En algunos casos, esta migraciones son temporales, de carácter estacional (unos meses al año), o durante periodos de varios

1. La información que se presenta sobre el caso de Amantaní se obtuvo en un trabajo de campo destinado a la realización de la tesis doctoral (Gascón, 1999), y que en parte ya ha sido publicada (entre otros, Gascón 1996, 2002, 2005a, 2011, y Pérez Berenguer\&Gascón, 1997). 
años. La construcción o la minería son actividades en las que se emplean una parte sustancial de estos migrantes. En otros casos la migración ya es definitiva, sin que eso implique una fractura en las relaciones sociales y económicas con la Isla.

Otra estrategia para combatir la reducción per capita de los ingresos agrarios ha sido la diversificación de las fuentes de ingresos: el transporte de mercancías y personas, el establecimiento de tiendas "de abarrotes" (ultramarinos) o la produccion artesanal para su venta fuera de la Isla, son algunas de estas actividades. En este esfuerzo por diversificar la economía doméstica, y aprovechando que el Titicaca es un atractivo de obligada visita para los toures que recorren el Sur del Perú y el norte de Bolivia, en la segunda mitad de la década de 1970 los amantaneños plantearon el desarrollo de la actividad turística. Considerando que este nuevo recurso tenía que favorecer a toda la comunidad, se estableció un sistema de turnos para distribuir a los visitantes entre las familias que deseaban alojar visitantes. Estas familias tuvieron que acondicionar una de sus habitaciones a los requisitos exigidos por el Estado y pagar un impuesto. El dispendio que ello suponía hizo que la mayoría de los isleños desistiesen y se conformasen con otros beneficios que se iban a gestionar de manera comunitaria, como la venta de artesanías. Pero un número importante de familias hizo la inversión y, con el permiso de alojamiento en la mano, se incluyeron en el sistema de turnos.

La población amantaneña tenía grandes expectativas en el turismo, pero pronto descubrió sus limitaciones. Por un lado, a una insuficiente promoción de la oferta se sumaba la exitos competencia de la vecina isla de Taquile, que había iniciado el desarrollo turístico con anterioridad y era más accesible por encontrarse a menos distancia de Puno, ciudad desde donde parten los toures por el Lago. Por otro, el conflicto armado entre el Estado y las guerrillas de Sendero Luminoso y el MRTA hundió en una fuerte crisis al sector turístico peruano desde principios de la década de 1980 hasta mediados de la siguiente. Los pocos viajeros que llegaban a Amantaní, sumado a su relativamente elevado número de habitantes, hizo fracasar el sistema de turnos. En este contexto, un determinado sector se hizo con el control de ese escaso turismo: los lancherso. Esto les fue posible porque controlaban el transporte entre la ciudad de Puno y la Isla; ellos traían a los turistas y los alojaban en sus hogares o en la de allegados. Merced al control de los medios de producción que permitían la llegada de los turistas, 90 familias acabaron monopolizando los ingresos por el alojamiento turístico. El resto de la población quedó excluido.

Cabe destacar que este sector lanchero había surgido en el proceso de diversificación económica antes indicado. Algunos isleños optaron por compatibilizar el trabajo agrícola con el transporte de personas y mercancías. A tal efecto organizaron cooperativas que les permitió reunir el capital necesario para la adquisición de una lancha y sus aperos. Patrones de lancha sólo pudieron ser campesinos que tenían un cierto nivel de capitalización, ya que se trataba de una actividad que requería una inversión inicial 
importante y cuya rentabilidad no estaba asegurada. Por el origen del capital invertido, estas unidades domésticas se pueden tipificar en dos grupos. Por un lado, aquellas cuyo cabeza de familia había tenido un cargo en las antiguas haciendas. Los capataces de las haciendas eran los que mayor acceso tenían al recurso tierra, pues tenían el derecho a usufructuar los lotes más grandes. Esto les permitió capitalizarse con mayor facilidad y aportar más dinero para la adquisición de las haciendas, gracias a lo cual pudieron adquirir una mayor cantidad de tierras que sus vecinos. El otro grupo estaba formado por campesinos que tuvieron un relativo éxito en la emigración y que, a su regreso, invirtieron las ganancias obtenidas en la creación de una cooperativa de transporte. De los 90 patrones que había en 1995, 62 formaban parte de este segundo grupo.

Si bien el turismo era insuficiente para generar beneficios a toda la comunidad, el monopolio por parte de este sector social permitió una ostensiblemente mejora de su nivel económico. Un cálculo estimativo indica que los ingresos por alojamiento fueron aproximadamente 22.500 \$US en 1995 (considerando una media diaria de cuatro turistas en temporada baja y 27 en temporada alta). Un reparto equitativo entre toda la población de los ingresos por alojamiento habría supuesto unos 5,6 \$ anuales per cápita. Sin embargo, su distribución se dio sólo entre lancheros. Teniendo en cuenta que en 1995 operaban quince embarcaciones en Amantaní, los ingresos por lancha fueron de 1.500 \$. El número de propietarios de embarcación total eran 90, lo que significa unos ingresos medios por lanchero de 250 \$ anuales.

Los ingresos que recibía cada lancha por el alojamiento se pueden considerar equitativos, pues se estableció un sistema de turnos entre ellas que aseguraba que todos realizaban el mismo número de viajes tanto en las temporadas altas como en las bajas. Sin embargo, no era así en la distribución de ingresos en cada lancha, pues el número de lancheros no era el mismo en cada embarcación. Y tampoco todos los patrones de una lancha tenían las mismas prerrogativas: los había que obtenían un mayor beneficio, ya que habían aportado más capital a la hora de crear la sociedad lanchera. A modo de ejemplo, la embarcación Virgen de la Candelaria. era de un solo propietario. En la Solimar, los propietarios eran cuatro, que se repartían los beneficios por igual. En la Independencia, el número era de diez, y se distribuían los ingresos porcentualmente a su aportación en la adquisición de la lancha, que era bastante desigual. Las diferencias eran, por tanto, notables ${ }^{2}$.

La frustración de las esperanzas depositadas en la nueva actividad por parte de la mayoría de los isleños hizo que desde la década de 1980 el "reparto de turistas" se convirtiera en el principal factor de conflictividad social. Pero lo que ahora nos interesa destacar es

\footnotetext{
2. Estimaciones establecidas a partir de datos obtenidos a través de la observación durante el tiempo que duró el trabajo de campo y en la información obtenida del Libro de Actas de la Gobernación de Amantaní, el Libro de Actas de la Municipalidad de Amantaní, el Libro de Actas del Sargento de Playa de Amantaní, el Libro de Actas de la Empresa de Transporte Turística Lacustre (empresa que reúne a todas las lanchas) y los libros de actas de diferentes asociaciones lancheras.
} 
que, además, la desigual distribución de sus beneficios se convirtió en el eje alrededor del cual se estructuró las diferencias socioeconómicas entre las familias amantaneñas. Otras actividades, como la agropecuaria o la emigración temporal jugaban un papel económico más importante en la economía global de la isla, pero la distribución de los ingresos que generaban era relativamente homogénea. En este contexto, que un pequeño grupo obtuviera un plus de ingresos le permitió consolidarse como el sector social mejor situado económicamente. Y les permitió controlar el cargo político más importante de la Isla: la Gobernación.

\section{EL CONTROL DEL PODER POLÍTICO}

Entre 1975, el año en que la Isla se planteó apostar por el turismo, y 1995, casi todos los gobernadores fueron propietarios de lanchas.

\begin{tabular}{|l|l|l|l|}
\hline Nombre & Año de gobierno & Religión $\left(^{*}\right)$ & Actividades económicas (**) \\
\hline Julián S. & 1968 & Adventista & Poseía mucho terreno \\
\hline Mariano Q.Y. & 1969 & Católico & Ganadero \\
\hline Aurelio Y. & 1970 & Católico & Lanchero. Propietario de tienda \\
\hline Manuel M. & 1971 & Adventista & Artesano peletero \\
\hline Julián J. & 1972 & Adventista & Propietario de tienda \\
\hline Mariano Q.P. & 1973 & Católico & Actividades diversificadas \\
\hline Félix J. & 1974 & Adventista & Propietario de tienda \\
\hline Ambrosio M. & 1975 & Católico & Lanchero \\
\hline Francisco Q. & 1976 & Católico & Lanchero. Propietario de tienda \\
\hline Esteban J. & 1977 & Católico & Lanchero \\
\hline Anastasio P. & 1978 & Católico & Lanchero \\
\hline Eleuterio Q. & 1979 & Católico & Lanchero \\
\hline
\end{tabular}




\begin{tabular}{|l|l|l|l|}
\hline Mariano P. & $1980-1981$ & Católico & Lanchero \\
\hline Toribio J. & $1982-1983$ & Católico & Lanchero \\
\hline Valentín Q. & 1984 & Católico & Lanchero \\
\hline Albino Y. & 1985 & Católico & Lanchero \\
\hline Gabriel C. & 1986 & Adventista & Lanchero \\
\hline Ignacio C. & 1987 & Adventista & Lanchero. Propietario de tienda \\
\hline Mariano B. & 1988 & Adventista & Lanchero \\
\hline Pedro J. & 1989 & Adventista & Exportación de artesanías \\
\hline Moisés Y. & 1990 & Adventista & Lanchero \\
\hline Alvredo V.C. & $1991-1992$ & Adventista & Lanchero \\
\hline Gonzalo P. & 1993 & Adventista & Lanchero \\
\hline Cresenciano Y. & $1994-1995$ & Adventista & Poseía mucho terreno \\
\hline
\end{tabular}

\footnotetext{
* $\quad$ Religión en el momento de ocupar el cargo de gobernador

* Característica económica que le permite tener un nivel económico alto
}

Tabla 1. Gobernadores de Amantaní y características económicas y religiosas

Fuentes: Libro de Actas de la Gobernación de Amantaní y entrevistas de campo.

Dos factores permitieron este control. El primero es que se trataba de un cargo oneroso. Conllevaba elevados gastos ceremoniales, y solo a principios de la década de 1990 empezó a recibir un presupuesto del Estado. Además el gobernador había de costearse los continuos desplazamientos a Puno para reunirse con las instituciones regionales de las que depende. Finalmente, el cargo comportaba mucha dedicación en tiempo: al gobernador no sólo le era imposible practicar la emigración estacional mientras ocupaba el cargo, sino que incluso debía descargar sobre su grupo doméstico, familiares, amigos y compadres buena parte del trabajo que normalmente realizaba en la Isla. Los costos del cargo de gobernador eran tan elevados que, en ocasiones, él y su familia debían 
ahorrar durante años, activar las relaciones de reciprocidad con sus allegados, emigrar temporalmente o incluso vender parte de su ganado. Por todo esto, sólo isleños con la suficiente capacidad de capitalización podían asumir el cargo. Y como hemos visto, a partir de la década de 1980, ser lanchero era el elemento identificativo del grupo económicamente preponderante.

El segundo factor que permitió el monopolio lanchero de la Gobernación fue el sistema de elección. El gobernador saliente elegía a tres candidatos para sustituirle. La terna se presentaba a la Asamblea Comunal, que escogía al nuevo gobernador entre los aspirantes. La estrategia del gobernador saliente era preparar una terna adecuada a los intereses del grupo: los candidatos siempre eran lancheros, allegados o personas no interesadas en los conflictos generados por la gestión del turismo.

Así, entre 1975 y 1995, solamente en dos ocasiones fueron elegidos no-lancheros, pero con la aquiescencia de éstos: eran individuos que no tenían ningún interés en participar en el conflicto por el recurso turismo, ya que se dedicaban con éxito a otras actividades.

Dos razones explican el interés por parte de los propietarios de las embarcaciones en asumir un cargo tan costoso en esfuerzo y recursos. Una era contrarrestar la oposición de ciertos sectores de la comunidad a su monopolio sobre el turismo: desde esta institución dificultaban cualquier intento de reglamentación para imponer un reparto equitativo. El éxito de los lancheros en su oposición a los intentos de establecer la figura del repartidor de turistas se debió tanto a su control de los "medios de producción" del turismo (las lanchas), como al respaldo de la principal institución política de Amantaní.

La otra era utilizar en su provecho la fuerza de trabajo isleña (en forma de labores comunales) y otros recursos gestionados por la Gobernación. Un repaso de los libros de actas de la Gobernación descubre que un importante porcentaje de los proyectos impulsados desde esta institución entre 1975 y 1995 coincidían con los intereses de los patrones de lanchas.

Esos proyectos se pueden clasificar en dos clases ${ }^{3}$. En primer lugar encontramos los de interés general:

1. Construcción del estadio de fútbol

2. Establecimiento y arreglos de escuelas

3. Establecimiento de colegio de secundaria

4. Establecimiento de huahuahuasis (jardines de infancia)

5. Construcción de sistema de agua potable

3. Información obtenida del Libro de Actas de Gobernación de Amantaní. 
6. Refacción de calles

7. Construcción de la Casa Artesanal

8. Reclamación de ayudas alimentarias en épocas de sequías

9. Reclamación de ayudas para reconstrucción de infraestructuras agrícolas

10. Refacción de la Iglesia

11. Creación de un sistema de irrigación (sin éxito)

12. Solicitud de préstamos agrarios a bajo interés (sin éxito)

Estos proyectos fueron la mayoría. Sin embargo hay que destacar que muchos comportaron un esfuerzo escaso para la Gobernación, ya que su financiación se logró accediendo a partidas del gobierno establecidas a tal fin. Por ejemplo, las infraestructuras educativas (proyectos del 2 al 4), que mejoraron considerablemente entre las décadas de 1970 y 1990, fueron el resultado natural de la formación de Amantaní como distrito y del crecimiento demográfico. La creación de huahuahuasis fue subvencionado de oficio por la institución gubernamental FONCODES (Fondo de Cooperacción para el Desarrollo Local). También la construcción de un sistema de agua potable (proy. 5) era consecuencia del proceso de distritalización. Las ayudas obtenidas ante situaciones de emergencia por catástrofes meteorológicas (proy. 8 y 9) provenían de programas gubernamentales creados a tal efecto. La construcción del estadio de fútbol (proy. 1) fue subvencionado casi en su totalidad por amantaneños emigrantes. Aquellos proyectos que necesitaban un mayor esfuerzo a la hora de buscar financiación por no ser considerada una obligación del Estado, nunca se llevaron a efecto. Así sucedió con el plan de irrigación de tierras de secano, que durante las décadas de 1970 y 1980 se veía como una solución al crecimiento demográfico (proy. 11).

El segundo grupo de proyectos lo forman aquellos que beneficiaron exclusiva o fundamentalmente al sector lanchero:

1. Construcciones y ampliaciones de muelles y atracaderos

2. Reconstrucciones de muelles y atracaderos dañados por tormentas

3. Legalización de Amantaní como destino turístico

4. Campañas en Puno para la promoción del turismo

5. Mejora de las infraestructuras y monumentos destinada a la promoción del turismo

6. Establecimiento de una fiesta artesanal destinada a la promoción del turismo 
7. Construcción de la Casa de Amantaní en Puno para promocionar el turismo y vender artesanías (

8. Construcción de la sede de la Gobernación

Las actas de la Gobernación reflejan que es extraño el año en que no se realizaban obras de consideración destinadas a mejorar o arreglar las infraestructuras portuarias (proy. 1 y 2). En la década de 1970 prácticamente todas los núcleos de población de la Isla tenían un atracadero; se trataban de espigones cuya utilidad era permitir la carga y descarga de personas y materiales desde las embarcaciones. Pero durante las décadas de 1980 y 1990, muchas se ampliaron y se convirtieron en muelles capaces de resguadar dos o más lanchas. El muelle principal fue también creciendo desde la década de 1970. El desarrollo de las instalaciones portuarias fue paralelo al aumento del número de lanchas en funcionamiento en Amantaní.

Eran los patrones de lancha los más beneficiados en la construcción y refacción de muelles, ya que les era imprescindibles para salvaguardar sus embarcaciones de los embates del oleaje y el viento. Su utilidad para el resto de la comunidad, en cambio, era dudosa, ya que el crecimiento de estas infraestructuras fue resultado del aumento del número de lanchas y no de sus requerimientos de transporte. Las quince lanchas que a mediados de la década de 1990 funcionaban eran excesivas para cubrir sus necesidades. Considerando sólo el transporte de isleños y mercanías, no era posible el mantenimiento de tantas embarcaciones. La formación de nuevas sociedades lancheras no era resultado de una demanda endógena, sino del deseo de participar en los beneficios del turismo.

No es necesario explicar que los lancheros eran los principales interesados en los proyectos dirigidos a favorecer el turismo (proyectos del 3 al 7). La construcción de la sede de la Gobernación (proy. 8) se realizó en 1991 con el aporte de una ONG. Su construcción permitió reducir los gastos ceremoniales de los gobernadores (recordemos que eran mayoritariamente lancheros), ya que hasta entonces las reuniones se realizaban en alguna habitación que para tal efecto debían acondicionar en sus casas, y esto comportaba un incremento de los gastos ceremoniales soportados por el cargo.

\section{CAMBIO RELIGIOSO}

Pero si los lancheros estaban dispuestos a invertir una parte de sus beneficios para mantener el control del principal cargo político de Amantaní, no lo estaban para destinar recursos en los mecanismos tradicionales de distribución de excedentes: el sistema de fiestas.

En Amantaní, la mayor parte de las fiestas públicas se mantenían gracias a los cargos de 
alferado y mayorazgo. El primero costeaba los gastos de tipo religioso, como las misas, los honorarios del sacerdote, las velas, etc. El segundo, los propiamente festivos como los bailes o la música. El extraordinario costo en trabajo y en bienes que comportaban las fiestas, y que los patrocinadores habían de soportar, era su característica más sobresaliente. Los cargos festivos eran ostentados en ocasiones por motu proprio. En otras, como resultado de la presión social. Y generalmente, por una combinación de ambos factores. El sistema de fiestas era, pues, coactiva y voluntaria a la vez: los más acomodados se veían motivados a asumir los cargos festivos porque la comunidad esperaba eso de ellos, porque sabían que su aceptación les daría prestigio entre la comunidad, y porque en caso de no aceptarlos podían ser castigados con la pérdida de poder social y político. Cabe destacar que en determinadas sociedades indígenas, el prestigio es un valor real y no simplemente simbólico (Carlsen, 1999). Es un mecanismo que ha sido estudiado en el mundo andino (Alberti \& Mayer 1974; Brass, 1986; Gose, 1994) y mesoamericano (Cancian, 1965; Wolf, 1959).

Tradicionalmente, los cargos festivos eran detentados por miembros de las familias campesinas más solventes; es decir, aquellas que usufructuaban más tierras. Sólo estos grupos domésticos poseían los suficientes medios de producción para acceder a los excedentes que permitían acumulara priori los costos de los festejos, o endeudarse a fin de poderlos sufragar.

Las tesis clásicas funcionalistas afirman que uno de los roles que juega la fiesta en América Latina es controlar la diferenciación campesina: el patrocinio de las fiestas obliga a los individuos con mayor capacidad económica a desprenderse de sus excedentes. De esta manera se consolida la solidaridad del grupo (e.g. Foster, 1953, 1972; Marzal, 1971). Pero si bien es indiscutible el papel que la fiesta tiene como mecanismo redistribuidor del excedente campesino, ello no comporta la igualdad del grupo. El empobrecimiento que un individuo puede sufrir al perder sus excedentes acumulados, o incluso los futuros al tener que endeudarse, no deja de ser un empobrecimiento ficticio, pues sigue manteniendo el control sobre los medios de producción que le otorgan su estatus socioeconómico. Además, quien tiene que patrocinar una fiesta no lo hace exclusivamente con su propio capital, sino que distribuye los costos al activar sus redes sociales: familiares y allegados participan de los gastos, ya sea ofreciendo bienes o con su trabajo (Gascón, 2005b; Mintz \& Wolf, 1950; Montes del Castillo, 1989).

Pero a medida que Amantaní se fue incorporando a la economía global, estos mecanismos redistributivos empezaron a entrar en crisis. Como ya hemos visto, el proceso de compraventa de las haciendas obligó a los amantaneños a salir de la Isla para capitalizarse. Este proceso les incorporó al mercado capitalista de bienes y de trabajo. Esta relación con el mercado capitalista se intensificó en los siguiente años, a la par que crecía la población y las consiguientes necesidades de nuevas fuentes de ingresos. En este nuevo contexto, los excedentes podían convertirse en capital inicial para nuevas actividades. Destinarlo a 
obtener prestigio dentro de la comunidad mediante la asunción de cargos festivos ya no tenía el interés de antaño.

Otro elemento que favoreció la crisis del sistema de fiestas fue la consolidación de la estructura burocrática del Estado. Tiempo atrás, asumir cargos festivos era un proceso necesario para alcanzar cargos políticos comunitarios de relevancia. Sin embargo, a medida que la estructura estatal se fue haciendo más patente, los cargos tradicionales (varayoc) perdieron poder frente a otros nuevos de carácter más formal (gobernador, alcalde). El interés de los amantaneños económicamente preponderantes por asumir cargos políticos no sólo se debía a una cuestión de prestigio, sino también a que ello les permitía controlar recursos públicos. En la medida que alcanzar estos cargos políticos ya no dependía de haber asumido previamente cargos festivos, su interés en asumirlos disminuyó. No obstante, la tradición y la presión de sus paisanos les obligaba a ello. En estas circunstancias, la conversión religiosa apareció como una estrategia que podía permitir liberarse de esas obligaciones ceremoniales.

Desde 1918 está documentada la presencia de la Iglesia Adventista del Séptimo Día (IASD) en Amantaní. Pero a mediados de siglo esta presencia era muy escasa. Sin embargo, en determinado momento empezó a tener predicamento entre el sector lanchero. Este interés se despertó a medida que este grupo fue convirtiéndose en el económicamente preponderante gracias a su monopolio del turismo.

El Adventismo, como la mayoría de las religiones protestantes o pentecostalistas que se han difundido por el Área andina, considera pernicioso todo gasto que no se destine a la creación de riqueza, sobre todo si va acompañado del consumo de productos tabú como el alcohol o la coca (La Serna Salcedo, 2004; Magny, 2008). Estos principios coincidían con los intereses de aquellos amantaneños deseosos de inhibirse de sus obligaciones comunitarias tradicionales para destinar sus excedentes a nuevas actividades propiciadas por el mercado capitalista. Es así que durante las décadas de 1970 y 1980 un grupo de isleños de nivel económico medio y alto se mostró propenso al cambio religioso. Eran campesinos que decidieron invertir sus excedentes, o el dinero obtenido trabajando en la emigración, en la adquisición de lanchas a motor para hacerse transportistas. Era una apuesta arriesgada y costosa, tanto por el capital inicial necesario en el momento de adquirir la embarcación, como por su mantenimiento posterior. Además, tenían la necesidad de reservar una parte sustancial de las ganancias en concepto de amortización, ya que tanto el motor como el casco tenían una duración determinada. Para estos amantaneños era crucial inhibirse de los gastos ceremoniales tradicionales. Solo así podían acumular y reservar el capital necesario para convertirse y mantenerse como transportistas. El Adventismo les ofreció esa posibilidad.

4. Oficio del gobernador de Capachica al subprefecto de Cercado de Puno (16 de septiembre de 1918). Archivo de la Prefectura de Puno. 
La siguiente tabla nos descubre como un porcentaje importante de los lancheros que habían en 1990 eran adventistas o lo habían sido en algún momento de la década anterior.

\begin{tabular}{|l|l|l|}
\hline Nombre de embarcación & No de Lancheros en $\mathbf{1 9 8 5}$ & No de Lancheros adventistas \\
\hline Arca de Noé & 5 & 3 \\
\hline Inca & 7 & 2 \\
\hline Halcón & 6 & 4 \\
\hline Tarzán & 9 & 7 \\
\hline Atún & 6 & 4 \\
\hline Picaflor & 5 & 0 \\
\hline Independencia & 10 & 5 \\
\hline La Paz & 9 & 4 \\
\hline TOTAL & $\mathbf{5 7}$ & $\mathbf{2 9}$ \\
\hline PORCENTAJE & & $\mathbf{5 0 , 9 0 \%}$ \\
\hline
\end{tabular}

Tabla 2. Lancheros adventistas en la década de 1980

Fuentes: Libro de Actas del Sargento de Playa de Amantaní, Libro de Actas de la Empresa de Transporte Turística Lacustre, y entrevistas de campo.

El porcentaje de adventistas que eran lancheros en 1985 era muy pequeño: algo más de un 6\%, si aceptamos el dato de 335 adventistas en Amantaní ofrecido por la Misión del Lago Titicaca. Sin embargo, se puede observar el mayor acercamiento de los lancheros a la IASD durante la década de 1980 si lo comparamos con la del resto de los isleños: mientras que el porcentaje de amantaneños adventistas era del $8.5 \%$, algo más de la mitad de los lancheros eran o habían sido adventistas.

Pero la tabla 2 descubre que la conversión religiosa entre los lancheros, aunque mayoritaria, no había sido generalizada. Varios factores actuaron para que así fuera. Por un lado, ser adventista conlleva una serie de sacrificios que no todos estaban dispuestos 
a realizar. Entre ellos, prohibiciones alimentarias (alcohol, coca, carne porcina), y tener que ceder a la IASD una parte de las ganancias (diezmo). Pero posiblemente la razón más significativa fue que no era necesaria la conversión de todos. Que una parte sustancial de los amantaneños considerados ricos fuesen adventistas sirvió de ejemplo y excusa al resto, lancheros o no, para también eximirse de sus obligaciones ceremoniales.

A modo de ejemplo podemos observar la evolución de la fiesta más importante de la comunidad: San Sebastián, que se celebra el segundo jueves del año. Tradicionalmente los propietarios de embarcaciones eran los encargados de cubrir la mayor parte de los gastos de esta festividad. Pero durante la segunda mitad de la década de 1970, los lancheros se descargaron de esa responsabilidad, aduciendo que los gastos podían y debían ser asumidos por la comunidad y con los alimentos donados por Cáritas. En la década de 1990 los gastos de la festividad eran sufragados por todos los isleños mediante cuota.

Las fiestas privadas también han visto reducido sus fastos. Antaño los festejos de bodas duraban tres días: el primero era subvencionado por la familia del novio, el segundo por el de la novia y el tercero por los padrinos. A mediados de la década de 1990 normalmente duraban un sólo día, en pocos casos dos. Quienes iniciaron esta práctica fueron los adventistas. En la dialéctica entre dejar de celebrar este tipo de fiestas, como su ética religiosa demanda, y mantenerlas, como propugna la tradición, optaron por una postura intermedia: reducir su duración y dispendio. Esta práctica fue rápidamente emulada por el resto de la comunidad.

\section{CAMBIO DE ESTRATEGIAS Y ALIANZAS: “CADUCIDAD” DEL ADVENTISMO PARA LOS INTERESES LANCHEROS}

A mediados de la década de 1990, el acceso a los beneficios del alojamiento turístico seguía siendo el elemento que marcaba las diferencias socioeconómicas en la Isla. Pero en los años inmediatamente anteriores diversos factores habían provocado cambios en las estrategias adoptadas por los amantaneños para su control.

Los nuevos lancheros

Entre 1982 y 1990 no se formó ninguna nueva sociedad lanchera en Amantaní. Sin embargo, en el periodo entre 1991 y 1995 surgieron siete, lo que prácticamente dobló el número de embarcaciones existentes. Y la mayor parte de estas nuevas sociedades (cinco) se establecieron entre 1994 y 1995. 


\begin{tabular}{|c|c|c|c|}
\hline $\begin{array}{l}\text { Nombre de } \\
\text { embarcación }\end{array}$ & $\begin{array}{l}N^{\circ} \text { de lancheros en } \\
1995\end{array}$ & \begin{tabular}{|l|} 
Lancheros \\
adventistas en 1995 \\
\end{tabular} & \begin{tabular}{|l}
$\begin{array}{l}\text { Lancheros } \\
\text { adventistas en } 1985\end{array}$ \\
\end{tabular} \\
\hline Arca de Noé & 5 & 3 & 3 \\
\hline Inca & 7 & 1 & 2 \\
\hline Halcón & 6 & 2 & 4 \\
\hline Tarzán & 9 & 5 & 7 \\
\hline Atún & 5 & 2 & 4 \\
\hline Picaflor & 5 & 0 & 0 \\
\hline Independencia & 10 & 2 & 5 \\
\hline $\mathrm{La} \mathrm{Paz}$ & 9 & 2 & 4 \\
\hline 8 de Diciembre & 5 & 1 & \\
\hline Sol y Mar & 7 & 3 & \\
\hline Solimar & 4 & 0 & \\
\hline Rey Marino & 4 & 0 & \\
\hline Pilcomayo & 5 & 0 & \\
\hline Estrella & 5 & 5 & \\
\hline Virgen de al C. & 1 & 0 & \\
\hline TOTAL & 87 & 26 & 29 \\
\hline PORCENTAJE & & $29,90 \%$ & $50,90 \%$ \\
\hline
\end{tabular}

Tabla 3. Número de lancheros adventistas por lanchas, en 1995, 1990 y 1985

Fuentes: Libro de Actas del Sargento de Playa de Amantaní, Libro de Actas de la Empresa de Transporte Turística Lacustre, y entrevistas de campo. 
Un factor que explica este fenómeno fue el nuevo impulso que vivió el turismo en el Perú tras la desarticulación de las cúpulas político-militares de Sendero Luminoso y el MRTA. Las perspectivas, que se evidenciaron ciertas, de que el turismo que llegaba a Amantaní iba a aumentar, animaron a muchos isleños a invertir en nuevas cooperativas lancheras.

Otro fue el reconocimiento tácito de que no se establecería ningún mecanismo de distribución del alojamiento turístico. El turismo seguía siendo considerado un recurso de propiedad comunal: todos los isleños tenían derecho a su acceso por el hecho de serlo, mientras que quienes no lo eran no tenían ese derecho. Pero era ya evidente que su explotación no se universalizaría a toda la comunidad. Para activar el derecho que todo isleño tiene al turismo era necesario poseer la herramienta que lo "produce": la lancha. Amantaneños que siempre se habían mostrado críticos con los patrones y reclamaban el establecimiento de un sistema de reparto equitativo cambiaron de estrategia: al menos cinco de las siete nuevas sociedades formadas entre 1991 y 1995 estaban compuestas por reconocidos detractores del monopolio lanchero.

Las estrategias y alianzas permutaron a la par que cambió el contexto. Por ejemplo, los nuevos lancheros, antaño críticos de los lancheros tradicionales, establecieron alianzas con éstos a la vez que entraron en la participación de los beneficios del turismo. El incremento del número de lanchas no supuso una reducción de los ingresos por embarcación, pues se dio paralelamente al aumento del número de visitantes. De hecho, el incremento de lanchas fue inferior al del turismo. No obstante, ante la mantenida tendencia de creación de nuevas sociedades ${ }^{5}$, las doce existentes antes de 1994 se plantearon una nueva estrategia consistente en generar una revolución en los medios de transporte lacustre: lanchas más cómodas y rápidas deberían permitirles seguir monopolizando el turismo y marginar a las nuevas. Para ello empezaron a buscar financiación y subsidios públicos.

\section{Abandono de la IASD}

El nuevo contexto también comportó un cambio en las estrategias religiosas. Como se observa en la tabla 3, el porcentaje de patrones adventistas se redujo notablemente durante la primera mitad de la década de 1990. Muchos abandonaron la IASD. Y la mayor parte de los patrones de las nuevas sociedades lancheras establecidas a partir de 1991 no eran, ni nunca fueron, adventistas: de los 31 lancheros de las siete sociedades formadas entre 1991 y 1995, sólo nueve eran adventistas. Si tenemos en cuenta que estas nuevas sociedades lancheras procedían de escisiones de otras más antiguas, el número de patrones advenedizos no-adventistas resulta mayor.

En parte, este fenómeno se explica por la rigidez de los principios adventistas a los que ya nos referimos anteriormente: pago de diezmo, prohibición de tomar alcohol, de mascar coca, de ingerir carne de ciertos animales, de participación en actividades festivas, etc.

5. En 1996 empezaron a funcionar otras dos embarcaciones. 
También porque muchos asumieron el cargo de gobernador, un cargo que comporta fuerte gastos ceremoniales; entre ellos, la obligación de promover y participar activamente en fiestas, y de convidar y tomar bebidas alcohólicas. Por esta razón, temerosos a las críticas que pudieran recibir de sus "hermanos en la fe", la mayoría dejaban de acudir temporalmente al Templo. Un alejamiento que muchas veces se convertía en un alejamiento permanente.

Pero la principal razón radicaba en que la función que había tenido el Adventismo para los lancheros, como estrategia para eximirse de ciertos gastos ceremoniales, estaba desapareciendo. Como ya hemos explicado, el sistema de fiestas basado en cargos religiosos, y los mecanismos de redestribución de excedentes que lo acompañaba, ya estaba desarticulado en la década de 1990. Si bien aún se mantenía una fiesta de estas características, la resistencia a participar en ella como alferado ya no suponía una transgresión social. Incluso los católicos habían adoptado prácticas iniciadas por los adventistas dirigidas a disminuir los costos festivos particulares. En la década de 1990 los amantaneños no sólo dependían del mercado capitalista económicamente, sino que estaban articulados a él ideológicamente. Sin duda, el Adventismo ayudó o aceleró este proceso, pero su función en este sentido era cada vez menos necesaria. Ya era posible sustraerse de las obligaciones ceremoniales tradicionales sin temer caer en el ostracismo.

En estas circunstancias, para muchos el Adventismo incluso se volvió una carga pesada. Un caso especialmente paradigmático es el de Alfredo V.C. A mediados de la década de 1990, Alfredo era uno de los principales líderes lancheros, había sido gobernador durante dos años, y en buena medida seguía controlando esta institución como personero en Amantaní de Cambio-90, el partido oficialista durante el gobierno de Alberto Fujimori. En la década de 1980, también se había convertido en uno de los dirigentes adventistas, y como tal era unode los fieles más estrictos en el cumplimiento de los preceptos religiosos. Pero en 1995, abandonó la IASD.

Los cargos políticos, sea cual sea su confesión, no pueden excusarse de participar en una serie de eventos que se contraponen con los principios adventistas: deben ir a la Iglesia (católica) los domingos, apoyar las fiestas y participar en ellas, tomar alcohol para granjearse o mantener el respeto de sus conciudadanos, etc. Durante los dos años que Alfredo fue gobernador intentó eximirse en lo posible de estas imposiciones, pero tampoco se negó a ellas cuando consideraba que podía estar en juego su autoridad. Esto le supuso ser objeto de críticas dentro de la comunidad adventista. Alfredo no abandonó el Templo durante su periodo como gobernador. Pero sus afanes políticos posteriores le obligaron a llevar un doble juego. Por una parte, pretendía mantener el apoyo que recibía de sus "hermanos en la fe". Pero por otro, su deseo por alcanzar el cargo de alcalde (el segundo cargo en importancia), al que se presentó en todas las elecciones municipales tras su periodo como gobernador, le obligaba a participar en las festividades y a convidar 
a sus vecinos a "tomar" (beber alcohol). Era una continuada campaña destinada a obtener las simpatías de los no-lancheros católicos. En los cálculos de Alfredo, obtener parte de ese voto era esencial para el éxito de su candidatura. En esta coyuntura, los preceptos adventistas se habían vuelto un lastre para sus intereses políticos. Llegó un momento en que no pudo sostener esta disyuntiva. Las críticas de sus "hermanos" a su comportamiento aumentaban. Finalmente, Alfredo decidió dejar de ser adventista. Al fin y al cabo, esta nueva estrategia ya no dañaba sus intereses económicos: ya había pasado por el cargo de gobernador $y$, como hemos explicado, la función del Adventismo como excusa para inhibirse de obligaciones ceremoniales estaba en crisis. Ahora su interés en seguir dentro de la IASD era el apoyo político que podía recibir de sus "hermanos en la fe". Pero mantener este apoyo suponía perder la posibilidad de ganar el del otro sector de isleños, mucho más numeroso.

\section{CONCLUSIONES}

La relación entre modernización ${ }^{6}$ y cambio religioso parece clara en el caso amantaneño: el Adventismo dio durante años cobertura ideológica a los mejor situados económicamente en sus iniciativas para capitalizarse y participar en el mercado a través del turismo. El dilema está en descubrir la naturaleza de esta relación.

Nuestro trabajo descubre que el éxito del Adventismo entre determinados sectores de la sociedad isleña se debió a que coincidía con sus intereses sociales y económicos, lo que hace pensar que la relación es causal. Y también, que el sentido de esta relación es la propugnada por los estudios marxistas: ciertos individuos aceptan la nueva religión para favorecer sus intereses individuales y de clase. Así se explica que, según el momento, fuesen unos sectores socioeconómicos y no otros los más receptivos al Adventismo. Pero esto no quiere decir que, en un efecto de retroalimentación, la población creyente no asumiera también conductas fomentadas por los principios adventistas. Los isleños adventistas se caracterizaban por su limpieza y cuidado en el vestir, por no consumir carne de cuy o de cerdo, por no beber alcohol, por mascar coca raramente, por acudir al templo los sábados, por negar la utilidad de los tradicionales rituales a la tierra, por dirigir sus ruegos a Dios y no a la Virgen o a los santos, etc., prácticas y creencias exógenas que van más allá de las "útiles" a sus intereses sociales, políticos o económicos. Y es que, como afirma Cox (1995), una religión sólo puede tener éxito si es capaz de ofrecer elementos a los acólitos para enfrentar los desafíos de la vida moderna, pero también si puede transformar la cosmovisión autóctona.

¿Pero la conversión religiosa fue una estratègia conscientemente planteada por el grupo que más beneficios obtuvo del turismo? La teoría constructivista desarrollada por

6. Hablamos de "modernización" en el sentido que le da Habermas (1985) para distinguirlo del concepto "modernidad": modernización hace referencia a la capitalización de los recursos, al desarrollo de las fuerzas productivas, y al desarrollo de formas de vida urbana y de la educación pública. Se sitúa, así, en el ámbito de lo socioeconómico. 
Bourdieu $(1980,1988)$ nos puede permitir encuadrar teóricamente lo acontecido en el caso amantaneño. Para Bourdieu el individuo es capaz de orientar su propia conducta de forma coherente, racional y ajustada a una finalidad, sin que por ello exista una voluntad expresa de coherencia, sea producto de un cálculo razonado o sea consciente del objetivo a conseguir. El principio generador de este fenómeno se encuentra en el concepto de habitus.

Dos elementos que caracterizan el habitus nos interesan para el caso que nos ocupa. El primero es que esta conducta, inconsciente y racional a la vez, y que tiene una presencia activa en la vida cotidiana del individuo, es producto de su historia, de su ambiente familiar y de la clase social a la que pertenece, sin que por ello se trate de un elemento estático. Dentro de esos condicionamientos de socialización, el habitus es capaz de ajustarse a nuevas situaciones y de crear nuevas prácticas. Es decir, acepta la innovación. El segundo elemento a destacar es que el habitus dificulta que el individuo aprehenda la realidad social objetivamente. Por el contrario, le da una percepción que depende de formas simbólicas institucionalizadas.

En el caso del lanchero amantaneño, la conversión religiosa era una actitud establecida por su habitus. Es un acto de innovación, que rompe con preceptos sociales y culturales previos. Pero un acto de innovación que no hace más que adecuar el habitus a un contexto cambiante. Y por otro lado, el adepto no interpreta su posicionamiento religioso como una estrategia de clase, aunque lo es. La conversión se basa en la creencia, por parte del neófito, de que la praxis y las enseñanzas propugnadas por la nueva religión son las correctas, sin advertir que así le parece a él porque coincide con sus intereses individuales y de grupo, y porque le otorga validez ética a las prácticas económicas y sociales que le son más beneficiosas.

Por tanto, en el caso amantaneño la religión no solo es un conjunto de creencias o un sistema que permite dar coherencia a un grupo social, como afirman las teorías de corte funcionalista, sino también un campo en el que se ponen en juego estrategias socioeconómicas (Worsley, 1980) y en el que se expresa la racionalidad reproductiva (Iturra, 1991), conscientemente o no.

En Amantaní, el turismo comunitario fue el principal motor que impulsó el cambio en los sistemas de conformación de prestigio social y político, para el que la adscripción religiosa sirvió de instrumento. Pero Amantaní llevaba décadas integrándose en el mercado. Es difícil creer que el proceso no hubiera sucedido también sin el desarrollo turístico de la Isla, como se ha observado en otros casos (e.g. Cruz Rodríguez, 2012; Plasencia Soto, 2007). Simplemente habría sido de otra manera. El caso amantaneño evidencia que el turismo es un vector más, entre otros, que contribuye a loscambios de carácter globalizador que las sociedades campesinas e indígenas vienen padeciendo desde mediados del siglo pasado. 


\section{REFERENCIAS BIBLIOGRÁFICAS}

Alberti, Giorgio y Enrique Mayer (1974) "Reciprocidad andina: ayer y hoy". En Giorgio Alberti y Enrique Mayer (eds.) Reciprocidad e Intercambio en losAndes. Lima: IEP, pp. 13-33.

Ávalos de Matos, Rosalía (1951) "Changements culturels dans les illes du lac Titicaca”. Travaux de l'Institut Francais d'Etudes Andines 3, pp. 40-50.

Bourdieu, Pierre (1980) Le Sens pratique. Paris: Les Éditions de Minuit.

Bourdieu, Pierre (1988) La distinción: Criterio y bases sociales del gusto. Madrid. Taurus. Orig.: 1979.

Brass, Tom (1986) "Cargos and Conflict: the Fiesta System and Capitalist Development in Eastern Peru”, Journal of Peasants Studies 13(3), pp. 46-62.

Cancian, Frank (1965) Economic and Prestige in a Maya Community: The Religious Cargo Sistem in Zinacantan. Stanford, CA: Stanford University Press.

Carlsen, Laura (1999) "Autonomía indígena y usos y costumbres: la innovación de la tradición", Revista Chiapas 7, pp. 45-70

Cohen, Erik (1971) Contemporary Tourism: Diversity and Change. Amsterdam: Elsevier Cox, Harvey (1995) Retour de Dieu: Voyage en pays pentecôtiste. Paris: Descleé de Brouvner.

Cruz Rodríguez, Edwin (2012) “Populism, Developmentalism and 'IndigenousProblem' in Bolivia and Ecuador", Asian Journal of Latin American Studies 25(4), pp. 79-102.

Foster, George M. (1953) "Cofradía and Compadrazgo in Spain and Spanish America". Southwestern Journal of Anthropology 9, pp. 1-28.

Foster, George M. (1972) Tzintzuntzan. México: FCE. Orig.: 1967.

Gascón, Jordi (1999) Gringos como en sueños: Diferenciación y conflicto campesino en el Sur Andino Peruano ante el desarrollo de un nuevo recurso: el turismo (Isla de Amantaní, Lago Titicaca). PhD dissertation, Universitat de Barcelona.

Gascón, Jordi (1996) "La gestión de un nuevo recurso: el turismo. Conflicto y lucha por su control en los Andes”. En Marie-Nöelle Chamoux y Jesús Contreras (eds.) La gestión comunal de recursos: Economía y poder en las sociedades locales de España y América Latina. Barcelona: Icaria, pp. 307-336.

Gascón, Jordi (2002) “El turismo como factor de globalización: Un caso andino”. En Tomás Calvo Buezas (ed.) Iberoamérica: Horizonte Tercer Milenio. Madrid: CEMIRA Universidad Complutense de Madrid. 
Gascón, Jordi (2005a) Gringos como en sueños: Diferenciación y conflicto campesino en los Andes Peruanos ante el desarrollo del turismo. Lima: IEP.

Gascón, Jordi (2005b) "Compadrazgo y Cambio en el Altiplano Peruano", Revista Española de Antropología Americana 35, pp. 191-206

Gascón, Jordi (2009) El turismo en la cooperación internacional.Barcelona: Icaria.

Gascón, Jordi (2011) “Turismo rural comunitario y diferenciación campesina: Consideraciones a partir de un caso andino" Mundo Agrario, 11(22)

Gose, Peter (1994) Deathy Waters and Hungry Mountains: Agrarian Ritual and Class Formation in an Andean Town. Toronto, Buffalo, London: University of Toronto Press.

Habermas, Jürgen (1985) Le discours philosophique de la modernité.Paris: Gallimard.

Iturra, Raul (1991) "Factores de reproducción social en sistema rurales: trabajo, producción de productores y pecado en aldeas campesinas". En Joan Prat, Ubaldo Martínez, Jesús Contreras e Isidoro Moreno (eds.) Antropología de los Pueblos de España. Madrid: Taurus, pp. 485-497.

Jitpakdee, Rungrawee y Gopal Bahadur Thapa (2012) "Sustainability Analysis of Ecotourism on Yao Noi Island, Thailand", Asia Pacific Journal of Tourism Research 17(3), pp. 301-325

La Serna Salcedo, Juna Carlos (2004) "Misiones adventistas como agentes de modernización y de articulación regional en la Selva Central peruana: Una acercamiento al proyecto misional indígena de Perené (1920-1948)”. En Dorothea Ortmann (ed.) Anuario de las Ciencias de la Religión: Las religiones en el Perú, hoy. Lima: UNMSM Concytec, pp. 243-285.

Litka, Stephanie (2013) “The Maya of Cobá: Managing Tourism in a Local Ejido”Annals of tourism Research 43, pp. 350-369

Magny, Caroline (2008) "When alcohol can no longer be drunk or coca leaves chewed. the case of the "protestants" in the Peruvian central Andes" Anthropology of food 6

Marzal, Manuel M. (1971) El mundo religioso de Urcos. Cusco: IPA.

Mintz, Sidney y Eric Wolf (1950) "An analysis of Ritual Co-parenthood (Compadrazgo)", Southwestern Journal of Anthropology 6(4), pp. 341-368.

Montes del Castillo, Ángel (1989) Simbolismo y poder: Un estudio antropológico sobre compadrazgo y priostazgo en una comunidad andina. Barcelona: Anthropos.

Netting, Robert McC (1997) Unequal commoners and uncommon equity: Property and a community among smallholders farmers. The Ecologist 27(1), pp. 28-33. 
Pérez Berenguer, Ester y Jordi Gascón (1997) "El impacto del turismo y de los proyectos de desarrollo de ONG en la estructura social y económica de dos comunidades andinas". Agricultura y Sociedad 87, pp. 225-251

Plasencia Soto, Rommel (2007) "La modernización rural en el valle del Mantaro: Una revisión”, Gazeta de Antropología 23, 6

Ruiz-Ballesteros, Eduardo y Doris Solís Carrión (2007)“Conclusiones y nuevas líneas de trabajo”. En Eduardo Ruiz-Ballesteros y Doris Solís Carrión (eds.)Turismo Comunitario en Ecuador: Desarrollo y sostenibilidad social. Quito: Abya Yala. pp. 315-333.

Vukonic, Boris (1996) Tourism and Religion. Oxford: Pergamon.

Worsley, Peter (1980) Al son de la trompeta final: Un estudio de los cultos cargo en Melanesia. Madrid: Siglo XXI. Orig.: 1957.

Wolf, Eric (1959) Sons of the Shaking Earth. Chicago: University of Chicago Press. 